\title{
Neutralization of Heparin for Extracorporeal Membrane Oxygenation
}

\author{
ECMO Setinde Heparin Nötralizasyonu
}

\author{
Benan BAYRAKCl
}

Hacettepe University, Faculty of Medicine, Department of Pediatric Intensive Care, Ankara, Turkey

Extracorporeal membrane oxygenation (ECMO) uses adapted conventional cardiopulmonary bypass technology to provide prolonged respiratory or cardio-respiratory support for patients who failed conventional intensive care management (1). ECMO provides the very sick child with cardiac and/or respiratory support until the child's own cardiac and/or respiratory system can provide the child's needs. ECMO is fairly complicated. Morbidity and mortality has a high potential in this patient population.

The most common complications of ECMO are hemorrhagic, related to the systemic heparinization (2). 20\% patients have clinically significant bleeding, including an intracranial hemorrhage $(\mathrm{ICH})$ rate of $6 \%$ to $17.5 \%$ (3). Severe $\mathrm{ICH}$ is the most common cause of death in the neonatal ECMO patients and associated with poor outcome in survivors (4). Thromboembolic events leading to cerebrovascular accidents have also remained one of the major concerns with the use of ECMO (5).

Alternatives to systemic heparinization include heparin bounded circuits and epsilon-aminocaproic acid infusions (6). The available knowledge on clinical applications of heparincoated perfusion is mainly based on short-term applications (7). Heparin bounded circuits do not completely eliminate the need for continuous heparin infusion. Also, aminocaproic acid has little value once bleeding has begun (6). In a recent study, either aprotinin or epsilon-aminocaproic acid administered in early postoperative period was shown to be ineffective in reducing postoperative bleeding (8). In this perspective, instead of lessening the heparin needed for the ECMO circuit, heparin blockage may theoretically be helpful, both for decreasing the risk of hemorrhage and for long term ECMO administration. Compartmentalizing the administration of heparin to the bypass circuit in Extracorporeal Membrane Oxygenation (ECMO) to prevent the bleeding complications without increasing the thrombosis risk may give a benefit. Protamine has been extensively used in the adult to reverse the effects of heparin after cardiopulmonary bypass surgery, but not in ECMO (9).

Like antibody antigen complexes, heparin-protamine complexes also activate the complement system. Heparin-protamine complexes must achieve a critical size in order to activate C1q. Heparin-protamine complexes secondarily initiate complement activation and eicosanoid generation, particularly thromboxane which may be responsible for many of the acute manifestations observed during protamine reversal of heparin anticoagulation. Complement activation is also related with the decrease in granulocyte count. Protamine reactions range from mild hypotension to severe cardiovascular collapse (10). Pulmonary hypertension and hemorrhagic pulmonary edema are other potential severe side effects of protamine (11). Peripheral platelet counts reduce $68 \%$ in animals receiving protamine. Also, there is a correlation between thrombocytopenia and development of hypotension (10). Anaphylactoid reactions due to protamine administration are mediated by complement activation leading to release of histamine, thromboxane and other vasoactive substances. These reactions may explain the pulmonary edema, pulmonary vasoconstriction, right ventricular failure and systemic hypotension following protamine administration (12)

Besides its primary action to increase the activity of antithrombin III, heparin has two other active sites, one for platelets and one for complement (9). Direct platelet activation by heparin reduces the benefit accrued from the use of this anticoagulant. Its effect on platelets is not uniform. Heparin increases the fibrinogen binding to platelets and stimulates aggregation (13). Rapid effects of heparin (5 min after $100 \mathrm{lU} / \mathrm{kg}$ ) are; significant fall in platelet count, platelet aggregation and enhanced release of thromboxane A2 (14).

Von Willebrand factor is produced in megakaryocytes and endothelial cells, is stored in alpha granule of platelets and in Weibel-Palade body off endothelial calls and is present in plasma and vascular sub endothelium. VWF contributes to both
Correspondence Address / Yazıșma Adresi:

Benan BAYRAKCI

Hacettepe University, Faculty of Medicine, Department of Pediatric Intensive Care, Ankara, Türkiye

E-mail: bbenan@yahoo.com
Received / Geliş tarihi : 21.06.2016 Accepted / Kabul tarihi : 25.08.2016 Online published Elektronik yayın tarihi

DOI: 10.12956/tjpd.2016.262 
platelet adhesion/aggregation and blood coagulation through its multiple adhesive functions for the platelet membrane receptors, glycoprotein Ib-IX-V complex, integrin alphallbbeta3, heparin, various types of collagen and coagulation factor VIII. Among various functions, the most characteristic feature of VWF is its determinant role on platelet thrombus formation under high-shear rate conditions (15).

ECMO circuit itself acts as a continued thrombotic stimulus that in turn results in continued fibrinolytic activity, but it is the effect of the contact and fibrinolytic activity on platelet function that actually results in a haemostatic defect.

Compartmentalizing the administration of heparin to the bypass circuit should greatly impact on one of the significant causes of morbidity and mortality in the use of ECMO which is intraventricular hemorrhage secondary to systemic heparinization. Defining and proving the safety and reliability of heparin neutralization procedure for ECMO is crucial for further spread of ECMO technique and may lead to the removal of "hemorrhage" from ECMO contraindications list.

\section{REFERENCES}

1. Firmin RK, Killer HM. Extracorporeal membrane oxygenation. Perfusion 1999;14:291-7.

2. Rais-Bahrami K, Short BL. The current status of neonatal extracorporeal membrane oxygenation. Semin Perinatol 2000;24:406-17.

3. Lustbader D, Fein A. Other modalities of oxygen therapy. Respir Care Clin N Am 2000;6:659-74.

4. Peek GJ, Sosnowski AW. Extracorporeal membrane oxygenation for paediatric respiratory failure. Bri Med Bull 1997;53:745-56.
5. Beghetti M, Rimersberger PC. Mechanical circulatory support in pediatric patients. Intensive Care Med 2000;26: 350-2.

6. Dickey LA, Butler TJ, Bergmann TM, Bates ME, Null DM. Selective heparinization of the extracorporeal membrane oxygenation circuit using continuous infusions of protamine and heparin in short-term pig model. Perfusion 1994;9:327-33.

7. Segesser LK. Heparin-bonded surfaces in extracorporeal membrane oxygenation for cardiac support. Ann Thorac Surg 1996;61:330-5.

8. Ray MJ, Hales MM, Brown L, O'Brien MF, Stafford EG. Postoperatively administered aprotinin or epsilon aminocaproic acid after cardiopulmonary bypass has limited benefit. Ann Thorac Surg 2001;72:521-6.

9. Peek GJ, Firmin RK. The inflammatory and coagulative response to prolonged extracorporeal membrane oxygenation. ASAIO J 1999;45:250-63.

10. Yang VC, Port FK, Kim JS, Teng CL, Till GO, Wakefield TW. The use of immobilized protamine in removing heparin and preventing protamine-induced complications during extracorporeal blood circulation. Anesthesiology 1991;75:288-97.

11. Boigner $H$, Lechner E, Brock H, Golej J, Trittenwein G. Life threatening cardiopulmonary failure following protamine reversal of heparin after cardiopulmonary bypass. Paediatr Anaesth 2001;11:729-32.

12. Malviya S. Monitoring and management of anticoagulation in children requiring extracorporeal circulation. Semin Thromb Hemost 1997;23:563-7.

13. Mikhailidis DP. Regarding 'heparin modulates integrin function in human platelets'. J Vasc Surg 2002;35:405-6.

14. Greenbaum RA, Barradas MA, Mikhailidis DR, Jeremy JY, Evans TR, Dandona P. Effect of heparin and contrast medium on platelet function during routine cardiac catheterisation. Cardiovasc Res 1987;21:878-85.

15. Sugimoto M, Miyata S. Functional property of von Willebrand factor under flowing blood. Int J Hematol 2002;75:19-24. 